Published in final edited form as:

Heart Fail Clin. 2014 July ; 10(3): 377-388. doi:10.1016/j.hfc.2014.04.003.

\title{
Epidemiology of heart failure with preserved ejection fraction
}

\author{
Charlotte Andersson, MD, PhD ${ }^{a, b}$ and Ramachandran S Vasan, MD ${ }^{a, c}$ \\ aFramingham Heart Study and Boston University School of Medicine, Boston, MA. \\ bDepartment of Cardiology, Gentofte Hospital, Hellerup, Denmark. \\ 'Section of Preventive Medicine and Cardiology, Boston University School of Medicine, Boston, \\ MA.
}

\begin{abstract}
Heart failure with preserved ejection fraction (HFPEF) is a common condition, especially among the elderly and in women, with the reported prevalence approaching $10 \%$ in women over the age of 80 years. With an increasing prevalence of hypertension, obesity, atrial fibrillation, and diabetes, and the growing elderly segment of the general population, the prevalence of HFPEF is projected to increase further. HFPEF presents a diagnostic challenge. As a consequence, studies differ widely in their reported incidence and mortality rates associated with this condition, although there is agreement that between a third and one half of heart failure patients in the community have HFPEF. Although several consensus statements and guidelines have been published during the last decade, some of the recent randomized clinical trials have reported low mortality rates, raising doubts whether all patients diagnosed with HFPEF do actually suffer from HFPEF (as opposed to misdiagnosis) or if the condition is heterogeneous by nature in terms of its etiology and prognosis. The overall reported prognosis of patients with HFPEF remains poor, with patients experiencing substantial comorbidity, high rates of repeated hospitalizations, and a high mortality. In both community-based and hospital-based cohorts, HFPEF was recently reported to be associated with approximately $159(154-165)$ deaths per 1000 person-years.
\end{abstract}

\section{Keywords}

epidemiology; heart failure; preserved ejection fraction; mortality; prognosis

\footnotetext{
(C) 2014 Elsevier Inc. All rights reserved.

${ }^{\mathrm{a}, \mathrm{b}}$ Corresponding author for proof and reprints: Charlotte Andersson, MD, PhD, Framingham Heart Study, Mt Wayte Avenue 73 , suite 2. Framingham, MA 01702-5827, (617) 817-3693, (508) 626-1262 (fax), ca@ heart.dk.

a,c Coauthor address: Ramachandran S Vasan, MD, Section of Preventive Medicine and Epidemiology, Boston University School of Medicine, 801 Massachusetts Avenue, Suite 470, Boston, MA 02118, USA, (508) 935-3450, (508) 626-1262 (fax)

Publisher's Disclaimer: This is a PDF file of an unedited manuscript that has been accepted for publication. As a service to our customers we are providing this early version of the manuscript. The manuscript will undergo copyediting, typesetting, and review of the resulting proof before it is published in its final citable form. Please note that during the production process errors may be discovered which could affect the content, and all legal disclaimers that apply to the journal pertain.

The authors have nothing to disclose.
} 


\section{Introduction}

Heart failure with preserved ejection (HFPEF) can be defined as a clinical syndrome in which the heart is unable to deliver the requisite amount of oxygen to the tissues commensurate with their metabolic needs, or does so but only at the expense of increased left ventricular filling pressures, despite a normal ejection fraction. Other terms used for this condition include 'backward heart failure' and diastolic heart failure. The reported prevalence of HFPEF is increasing, in part due to a greater awareness of the diagnosis, refined echocardiographic techniques, and also due to changes in demographics (such as ageing of the population), and higher burden of lifestyle-related risk factors (such as obesity and diabetes). For many years, HFPEF has remained a clinical illusive concept with lack of both national and international consensus on criteria for its diagnosis. $(1,2)$ There are no clinical symptoms or signs that have a high sensitivity or specificity for the diagnosis of HFPEF, and the pathophysiological mechanisms underlying the condition are not well established. Moreover, patients with HFPEF often have concomitant comorbidities that may either mask or confound the diagnosis.

The current American Heart Association/American College of Cardiology and European Society of Cardiology guidelines both recommend that a diagnosis of HFPEF should be based on the presence of the three following features: 1. Signs and symptoms consistent with a diagnosis of heart failure; 2 . Absence of depressed ejection fraction (i.e., a left ventricular ejection fraction $[\mathrm{LVEF}] 250 \%$ ); and 3 . Objective measures showing an impaired LV diastolic function. $(3,4)$ Furthermore, the clinical findings should not be explainable by other conditions, such as a primary volume overload state or chronic pulmonary disease. The diagnostic criteria are still subject to variability between hospitals and across studies. Of note, no single non-invasive measure of LV diastolic function is optimally accurate and sensitive for establishing a diagnosis of LV diastolic dysfunction (the third criterion). Therefore, guidelines concur that LV diastolic function should be measured by more than one technique in these patients, where feasible. Additionally, guidelines are not specific regarding which combination of symptoms and signs adequately and accurately establishes a clinical diagnosis of heart failure.

Most symptoms and clinical findings, especially those that are present in milder states of HFPEF (such as reduced exercise capability or mild ankle edema) are inherently nondiscriminatory and may be caused by a variety of clinical conditions, including chronic pulmonary disease, physical deconditioning, obesity, and/or renal disease. Symptoms and signs of more severe heart failure (like paroxysmal nocturnal dyspnea and pulmonary edema) are more specific, but have a lower sensitivity. The Framingham Heart Study heart failure criteria are among the most commonly used and are widely accepted for an initial evaluation of suspected heart failure. They are based on an algorithm that combines different objective signs for diagnosing heart failure (Table 1) and are intended for epidemiological settings. Because there is no gold standard for the clinical diagnosis, however, validation of different algorithms and measures to diagnose HFPEF is somewhat challenging. As an illustrative example, in the recent placebo controlled randomized trial of spironolactone (the Aldo-DHF trial) only 1 of 422 patients died during 12 months of follow-up, which is much lower than the mortality expected in HFPEF patients based on prior reports from other 
observational and clinical trials. The observed low mortality of these patients in some series has led some investigators to question the diagnosis of HFPEF itself with the added speculation that some of these patients may not have heart failure. $(1,5)$ The most common heart failure symptoms for inclusion in the Aldo-DHF trial were fatigue (59\%) and nocturia $(80 \%)$, which are per se not specific enough for a diagnosis of heart failure (compared to the more exhaustive Framingham criteria).(6) Supporting the notion that HFPEF may be over diagnosed, Caruana et al. reported that, in a sample of consecutively referred patients with suspected heart failure and normal systolic function but without atrial fibrillation, or valve disease, an alternative diagnosis (such as obesity, reduced pulmonary capacity, or coronary artery disease) was present in the majority of patients even though they had demonstrable LV diastolic dysfunction.(5) The authors, therefore, concluded that few if any patients satisfied the criteria for a diagnosis of pure diastolic heart failure.(5) The echocardiographic findings suggestive of heart failure was recently compared with clinical findings based on the Framingham criteria in 216 consecutive patients admitted with suspected heart failure to a cardiology unit at an academic hospital in Spain.(7) The authors concluded that the Framingham criteria were very sensitive (92\%) and moderately specific (72\%) for diagnosing heart failure. The absence of positive Framingham criteria conclusively ruled out heart failure with reduced ejection fraction (HFREF), and almost conclusively ruled out HFPEF.(7) The recent guidelines suggesting a combination of echocardiography (demonstrating normal LVEF and LV diastolic dysfunction) and clinical signs and symptoms of heart failure (preferably in accordance with the Framingham criteria) seems, therefore, both appropriate and necessary to make a correct clinical diagnosis of HFPEF.

Despite limitations and inconsistency in the diagnosis of HFPEF, numerous reports in the literature have provided valuable data regarding the condition. In the present review, we will summarize these epidemiological studies. It should be noted, however, that HFPEF still receives much less attention than HFREF (both in clinical care and in published guidelines), perhaps because there is no clear mortality benefit associated with any pharmacological treatment for the former.

\section{Risk factors}

It may be challenging to elucidate the relative contributions of one or more risk factors to the overall burden of HFPEF in the community. Indeed, the prevalence of risk factors may vary between individuals with HFPEF, and these risk factors likely interact (conjointly and synergistically) to augment risk of developing HFPEF.(8) Overall, the most important risk factors for developing HFPEF include hypertension,(9) older age, and female sex. $(10,11)$ Indeed, the prevalence of HFPEF in community-based settings increases rapidly with advancing age, especially so in women, approaching $10 \%$ in women aged 80 years or more in a recent Portuguese survey.(12) Other comorbidities frequently associated in HFPEF patients and likely contributing to disease risk include coronary artery disease, atrial fibrillation,(13) obesity,(14) and diabetes.(15) Reports of large-scale trials or clinical databases with HFPEF patients have shown that hypertension is present in 50-90\% of patients with preserved ejection fraction, which is higher than its prevalence in the general population, and somewhat higher than in patients with HFREF.(16-20) Although high blood pressure is causally related to HFPEF incidence, a history of hypertension has shown to be 
associated with a neutral or paradoxical survival benefit after the onset of heart failure patients.(21) Nonetheless, a history of hypertension has shown to be associated with high mortality, especially among those with a restrictive LV filling pattern (the ultimate consequence of hypertension and cardiac hypertrophy).(22)

In a general community, Lee et al. sought to clarify the etiology of incident heart failure according to preserved (defined as LVEF $\geq 45 \%$ ) or reduced ejection fraction (LVEF <45\%) in the Original and Offspring cohorts of Framingham Heart Study. Using a hierarchical schema for attributing heart failure sequentially to different causes (weighting coronary insufficiency highest followed by valve disease followed by hypertension), hypertension was shown to be the primary cause of HFPEF in $36 \%$ of the cases; $37 \%$ and $11 \%$ of the cases were attributable to coronary artery disease and valve disease, respectively, whereas the remaining 16\% were unclassified.(23) Several studies have supported the notion that global myocardial ischemia may cause diastolic dysfunction and HFPEF.(24-26) Indeed the active part of the myocardial relaxation has shown to be the most energy-consuming step of the whole cardiac cycle. Consequently, ischemia initially affects LV diastolic function.(27) Thus, it is not surprising that, especially in the presence of key risk factors such as diabetes and hypertension, patients with stable coronary artery disease may develop HFPEF.(28) A contributing reason for the high risk of HFPEF among elderly and women could be that these demographic subsets often have microvascular heart disease (compared to younger men who more often develop macrovascular heart disease and as a result have a greater occurrence of HFREF).(29) This was recently confirmed in an analysis of the Framingham Heart Study Original and Offspring cohorts, where men and women were at similar risks of developing HFPEF, whereas men were at higher risk of developing HFREF and that this excessive this risk was mainly related to interim myocardial infarction.(30) Similar findings were recently demonstrated in the Prevention of Renal and Vascular End-stage Disease (PREVEND) community-based cohort study (although women were reported to be at higher risk of HFPEF compared with men in this study).(31) The incidence of HFPEF increases rapidly with age.(32) For example, in a large Danish cohort study of consecutively hospitalized heart failure patients between 2002 and 2003, the prevalence of HFPEF was significantly higher among elderly patients compared with younger patients (53\% vs. $36 \%$ in patients below and above or equal to 85 years of age).(33)

Other conditions associated with an increased risk of HFPEF include sleep apnea,(34) chronic obstructive pulmonary disease,(35) renal dysfunction,(31) dyslipidemia/cardiac steatosis,(36) rheumatoid arthritis and other systemic inflammatory diseases,(37-40) and select medications (especially antineoplastic therapy)(41) although the exact and independent role of these contributing conditions to the risk of HFPEF remains to be determined.

\section{Subclinical disease measures and biomarkers relating to HFPEF}

HFPEF may have a long preclinical phase, and the identification of subclinical disease by echocardiography (LV hypertrophy and diastolic dysfunction) and biomarkers can help identify those at high risk of HFPEF. Left ventricular diastolic dysfunction measured by transthoracic echocardiography was demonstrated to be a very common and independent 
predictor of overt HFPEF in an asymptomatic sample of middle-aged to elderly individuals in the Olmsted County Heart Function Study (24\% and 39\% had diastolic dysfunction at baseline and after 4 years, respectively).(42) A separate report from Framingham confirmed this association.(43) Moreover, echocardiographic LV hypertrophy in asymptomatic middleaged and elderly individuals was recently shown to be an independent long-term predictor of HFPEF in the Framingham Heart Study, with age- and sex adjusted 10-year incidence rates of heart failure corresponding to $0.77(0.33-1.21)$ per 100 persons among those with normal left ventricle, 1.57 (0.37-2.72) among those with concentric hypertrophy, and 2.11 (1.033.14) among those with eccentric hypertrophy.(44) A recent study based on the Dallas Heart Study cohort further showed that among asymptomatic individuals with hypertrophy those with a particularly malignant subtype were characterized by elevated circulating levels of troponin T and NT-proBNP.(45) As discussed in detail by Cheng et al., there are several other circulating novel biomarkers that are associated with incident HFPEF and are informative about the clinical course of disease, including GDF-15, cystatin C, resistin, and galectin-3.(46)

\section{Prevalence and Incidence of HFPEF}

Whereas the incidence of HFPEF seems to be relatively stable, its prevalence may have increased over the last couple of decades. The proportion of HFPEF among all heart failure cases lies somewhere between $44 \%$ and $72 \%$, with a suggestion of a temporal increase in the proportion of HFPEF cases in recent years.(32) In 2010, a total of 1,023,000 people were discharged with a primary diagnosis of heart failure from US hospitals.(47) This number was unchanged as compared with the year 2000 and was higher than the numbers diagnosed in the 1990's.(47) Among patients admitted with decompensated heart failure to Mayo Clinic Hospitals in Olmsted County, Minnesota, the proportion of patients with HFPEF was shown to increase from approximately $38 \%$ in 1987 to $54 \%$ in 2001 - an increase that was solely explained by an increase in numbers of admissions for HFPEF and not by a decrease in numbers of individuals with HFREF.(48) During the same time period, the proportion of heart failure patients who had hypertension, diabetes, or atrial fibrillation increased.(48) This is consistent with the current global increases in the prevalence of hypertension, obesity, diabetes, and atrial fibrillation, and underscores the importance of HFPEF as a potential growing global public health problem.(49) A similar increasing trend in the prevalence of HFPEF was recently demonstrated in a survey of 275 hospitals in the 'Get With the Guidelines-Heart Failure' report from January 2005 to October 2010.(50) Based on data from a sample of individuals in the Olmsted County, Rogers et al. reported that ageadjusted incidence rates of overall heart failure between 1979 and 2000 were not declining in either men or women.(51)

\section{World Wide/Regional Incidence and Mortality Rates}

In 2009, 1 in 9 death certificates (corresponding to 275,000 individuals) in the US had heart failure registered as a primary or contributing cause of death.(47) A common belief has however been that HFPEF is something you 'die with' and not 'die of'.(52) Indeed, individuals with HFPEF often suffer from a significant burden of comorbidities. Yet, even after adjustment of comorbid conditions, the mortality rates associated with HFPEF are 
higher compared with the background population of similar age. For example, data from the Framingham Heart Study suggested that individuals with HFPEF and HFREF had a comparable 4-fold increase in relative risk of death, compared with age-matched controls. (53) Moreover, the survey from the Olmsted County showed that mortality rates of HFPEF did not improve between 1987 and 2001, as opposed to improvement in the outcomes for HFREF.(48) The most common cause of death in HFPEF has however been suggested to be due to non-cardiovascular causes, perhaps supporting the notion that HFPEF is not something one necessarily dies of, but more likely one dies with.(54) Yet, some uncertainty remains in this area. A very recent review of contemporary epidemiological and clinical randomized trials concluded that the majority of deaths were, indeed, of cardiovascular causes (51-60\% for epidemiological studies, and $>70 \%$ in clinical randomized trials).(55) Campbell et al. compared the mortality rates of patients from clinical HFPEF trials with patients from clinical trials of other cardiovascular diseases and similar concluded that, although having comparable prevalence of comorbidities, age, and gender, those with HFPEF had significantly worse outcomes compared with patients from other cardiovascular trials, suggesting that the high mortality rates seen for patients with HFPEF cannot be completely explained by comorbidity burden.(56)

It is interesting to note that mortality rates for HFPEF have varied widely in different reports, probably as a consequence of differences in diagnostic criteria and clinical settings (population based vs. in hospitalization settings vs. clinical trials). Tables 2 and 3 summarize selected characteristics and mortality of some of the most recent clinical trials and population-based samples. Of note, the echocardiographic characteristics displayed rather larger differences between the different samples. There were low to very low mortality rates in these clinical trials, as compared with those reported in community based or hospitalization settings. The Meta-Analysis Global Group in Chronic Heart Failure (MAGGIC) recently evaluated mortality rates in 41,972 patients, of which 10,347 (24.7\%) had HFPEF, from 18 observational and clinical trial studies.(16) There were 121 (95\% confidence intervals 117-126) deaths per 1000 person-years in the HFPEF group and 141 (138-144) deaths per 1000 person-years in the HFREF group. When excluding randomized clinical trials, however, mortality rates were more similar for HFPEF and heart failure with reduced ejection fraction, 146 (138-154) vs. 159 (154-165) deaths per 1000 person-years, respectively.(16) Similar, in a French cohort of patients hospitalized for the first time with heart failure, 5-year survival rates were not significantly different in patients with preserved and reduced ejection fraction ( $43 \%$ vs. $46 \%, \mathrm{p}=0.95)$.(57) Comparable high mortality rates were also found in a Canadian survey of patients hospitalized with heart failure: 30-day mortality rates were $5.3 \%$ vs. $7.1 \%(\mathrm{p}=0.08)$, and 1 -year mortality rates of $25.5 \%$ vs. $22.2 \%$ ( $\mathrm{p}=0.08$ ) for patients with HFPEF and HFREF, respectively.(40) Yet, however, one metaanalysis based on prospective observational studies, showed that the mortality of HFPEF was only 50\% that of HFREF.(58)Perhaps, prognosis in HFPEF and HFREF are more similar once patients have been hospitalized.(55)

Comprehensive studies of worldwide trends in incidence, prevalence, and heart failure related mortality are lacking, but HFPEF seems to be an increasingly common disease in several parts of the "westernized" world. For example, heart failure is now a common disease with significant impact on the health care system in several parts of Africa, because 
the rapid adaption to westernized living habits (i.e., sedentary lifestyle, consumption of fastfood, and salt, with increasing prevalence of hypertension and obesity), despite the fact that coronary artery disease is still rather uncommon in the African continent.(59)

\section{Clinical Correlation}

Patients with HFPEF seem to have comparable hospitalization rates to patients with HFREF. (10) Because approximately $50 \%$ of all patients with heart failure have preserved ejection fraction, about half of the total burden of heart failure costs is presumably due to HFPEF. In 2010 , there were 1,801 million physician office visits with heart failure as the primary diagnosis.(47) The number of emergency room visits due to heart failure was 668,000 and the number of outpatient visits was 293,000 in 2009.(47) Further, the majority of hospitalizations among heart failure patients $(>50 \%)$ are known to be for non-cardiac causes that were not included in the statistics above.(60) Although heart failure hospitalization rates seem to have declined during the past decade (age-, sex-, and race-adjusted rates were reported to be 2845 per 100,000 person-years in 1998, and 2007 per 100,000 person-years in 2008 ( $p<0.001$ ) among Medicare beneficiaries), (61) the clinical and community burden of heart failure is still high and is expected to be rising, because of the growing amount of elderly individuals. The recent American Heart Association's Heart Disease and Stroke Statistics projections pointed towards an increase of almost $120 \%$ in total cost of heart failure in US in 2030, as compared with 2013 (from 32 to 70 billion dollars).(47)

\section{Summary}

HFPEF still poses a diagnostic challenge and mortality rates associated with the condition vary widely between clinical trials, epidemiological cohort studies, and hospitalization settings, partly because of differences in diagnostic criteria. In community-based surveys the prevalence of HFPEF approaches $10 \%$ for people $>80$ years of age; and incidence rates seem stable in the face of a growing prevalence. The overall prognosis of patients with HFPEF remains poor. Thus, prevalence as well as costs related to HFPEF is expected to increase in the US as well as internationally. Given that HFPEF poses considerable societal burden, efforts are warranted to reduce its burden through better control of modifiable risk factors like hypertension, diabetes and obesity.

\section{Acknowledgments}

This work was supported in part by N01-HC-25195. Dr. Andersson was supported by an independent research grant from the Danish agency for science, technology, and innovation (the Danish Medical Research Council, grant no. FSS - 11-120873).

\section{References}

1. Cleland JG, Pellicori P. Defining diastolic heart failure and identifying effective therapies. JAMA : the journal of the American Medical Association. 2013; 309:825-826. [PubMed: 23443447]

2. Vasan RS, Levy D. Defining diastolic heart failure: a call for standardized diagnostic criteria. Circulation. 2000; 101:2118-2121. [PubMed: 10790356]

3. McMurray JJ, Adamopoulos S, Anker SD, et al. ESC Guidelines for the diagnosis and treatment of acute and chronic heart failure 2012: The Task Force for the Diagnosis and Treatment of Acute and Chronic Heart Failure 2012 of the European Society of Cardiology Developed in collaboration with 
the Heart Failure Association (HFA) of the ESC. European heart journal. 2012; 33:1787-1847. [PubMed: 22611136]

4. Yancy CW, Jessup M, Bozkurt B, et al. 2013 ACCF/AHA guideline for the management of heart failure: executive summary: a report of the American College of Cardiology Foundation/American Heart Association Task Force on practice guidelines. Circulation. 2013; 128:1810-1852. [PubMed: 23741057]

5. Caruana L, Petrie MC, Davie AP, McMurray JJ. Do patients with suspected heart failure and preserved left ventricular systolic function suffer from "diastolic heart failure" or from misdiagnosis? A prospective descriptive study. Bmj. 2000; 321:215-218. [PubMed: 10903655]

6. Edelmann F, Wachter R, Schmidt AG, et al. Effect of spironolactone on diastolic function and exercise capacity in patients with heart failure with preserved ejection fraction: the Aldo-DHF randomized controlled trial. Jama. 2013; 309:781-791. [PubMed: 23443441]

7. Maestre A, Gil V, Gallego J, Aznar J, Mora A, Martin-Hidalgo A. Diagnostic accuracy of clinical criteria for identifying systolic and diastolic heart failure: cross-sectional study. Journal of evaluation in clinical practice. 2009; 15:55-61. [PubMed: 19239582]

8. Maurer MS, King DL, El-Khoury Rumbarger L, Packer M, Burkhoff D. Left heart failure with a normal ejection fraction: identification of different pathophysiologic mechanisms. Journal of cardiac failure. 2005; 11:177-187. [PubMed: 15812744]

9. Vasan RS, Levy D. The role of hypertension in the pathogenesis of heart failure. A clinical mechanistic overview. Archives of internal medicine. 1996; 156:1789-196. [PubMed: 8790072]

10. Fonarow GC, Stough WG, Abraham WT, et al. Characteristics, treatments, and outcomes of patients with preserved systolic function hospitalized for heart failure: a report from the OPTIMIZE-HF Registry. Journal of the American College of Cardiology. 2007; 50:768-777. [PubMed: 17707182]

11. Vasan RS, Benjamin EJ, Levy D. Prevalence, clinical features and prognosis of diastolic heart failure: an epidemiologic perspective. Journal of the American College of Cardiology. 1995; 26:1565-1574. [PubMed: 7594087]

12. Ceia F, Fonseca C, Mota T, et al. Prevalence of chronic heart failure in Southwestern Europe: the EPICA study. European journal of heart failure. 2002; 4:531-539. [PubMed: 12167394]

13. Maisel WH, Stevenson LW. Atrial fibrillation in heart failure: epidemiology, pathophysiology, and rationale for therapy. The American journal of cardiology. 2003; 91:2D-8D.

14. Kenchaiah S, Evans JC, Levy D, et al. Obesity and the risk of heart failure. The New England journal of medicine. 2002; 347:305-313. [PubMed: 12151467]

15. Fang ZY, Prins JB, Marwick TH. Diabetic cardiomyopathy: evidence, mechanisms, and therapeutic implications. Endocrine reviews. 2004; 25:543-567. [PubMed: 15294881]

16. Meta-analysis Global Group in Chronic Heart F. The survival of patients with heart failure with preserved or reduced left ventricular ejection fraction: an individual patient data meta-analysis. European heart journal. 2012; 33:1750-1757. [PubMed: 21821849]

17. Massie BM, Carson PE, McMurray JJ, et al. Irbesartan in patients with heart failure and preserved ejection fraction. N Engl J Med. 2008; 359:2456-2467. [PubMed: 19001508]

18. Cleland JG, Tendera M, Adamus J, et al. The perindopril in elderly people with chronic heart failure (PEP-CHF) study. Eur Heart J. 2006; 27:2338-2345. [PubMed: 16963472]

19. Chinali M, Joffe SW, Aurigemma GP, Makam R, Meyer TE, Goldberg RJ. Risk factors and comorbidities in a community-wide sample of patients hospitalized with acute systolic or diastolic heart failure: the Worcester Heart Failure Study. Coronary artery disease. 2010; 21:137-143. [PubMed: 20305550]

20. Redfield MM, Chen HH, Borlaug BA, et al. Effect of phosphodiesterase-5 inhibition on exercise capacity and clinical status in heart failure with preserved ejection fraction: a randomized clinical trial. Jama. 2013; 309:1268-1277. [PubMed: 23478662]

21. Guder G, Frantz S, Bauersachs J, et al. Reverse epidemiology in systolic and nonsystolic heart failure: cumulative prognostic benefit of classical cardiovascular risk factors. Circulation Heart failure. 2009; 2:563-571. [PubMed: 19919981] 
22. Andersson C, Gislason GH, Weeke P, et al. The prognostic importance of a history of hypertension in patients with symptomatic heart failure is substantially worsened by a short mitral inflow deceleration time. BMC cardiovascular disorders. 2012; 12:30. [PubMed: 22533520]

23. Lee DS, Gona P, Vasan RS, et al. Relation of disease pathogenesis and risk factors to heart failure with preserved or reduced ejection fraction: insights from the framingham heart study of the national heart, lung, and blood institute. Circulation. 2009; 119:3070-3077. [PubMed: 19506115]

24. Mogelvang R, Sogaard P, Pedersen SA, Olsen NT, Schnohr P, Jensen JS. Tissue Doppler echocardiography in persons with hypertension, diabetes, or ischaemic heart disease: the Copenhagen City Heart Study. European heart journal. 2009; 30:731-739. [PubMed: 19176536]

25. Hoffmann S, Jensen JS, Iversen AZ, et al. Tissue Doppler echocardiography improves the diagnosis of coronary artery stenosis in stable angina pectoris. European heart journal cardiovascular Imaging. 2012; 13:724-729. [PubMed: 22323549]

26. Garcia-Fernandez MA, Azevedo J, Moreno M, et al. Regional diastolic function in ischaemic heart disease using pulsed wave Doppler tissue imaging. European heart journal. 1999; 20:496-505. [PubMed: 10365286]

27. Nagueh SF, Rao L, Soto J, Middleton KJ, Khoury DS. Haemodynamic insights into the effects of ischaemia and cycle length on tissue Doppler-derived mitral annulus diastolic velocities. Clinical science. 2004; 106:147-154. [PubMed: 12968949]

28. Lewis EF, Solomon SD, Jablonski KA, et al. Predictors of heart failure in patients with stable coronary artery disease: a PEACE study. Circulation Heart failure. 2009; 2:209-216. [PubMed: 19808342]

29. Vaccarino V. Ischemic heart disease in women: many questions, few facts. Circulation Cardiovascular quality and outcomes. 2010; 3:111-115. [PubMed: 20160161]

30. Ho JE, Lyass A, Lee DS, et al. Predictors of new-onset heart failure: differences in preserved versus reduced ejection fraction. Circulation Heart failure. 2013; 6:279-286. [PubMed: 23271790]

31. Brouwers FP, de Boer RA, van der Harst P, et al. Incidence and epidemiology of new onset heart failure with preserved vs. reduced ejection fraction in a community-based cohort: 11-year followup of PREVEND. European heart journal. 2013; 34:1424-1431. [PubMed: 23470495]

32. Hogg K, Swedberg K, McMurray J. Heart failure with preserved left ventricular systolic function; epidemiology, clinical characteristics, and prognosis. Journal of the American College of Cardiology. 2004; 43:317-327. [PubMed: 15013109]

33. Mogensen UM, Ersboll M, Andersen M, et al. Clinical characteristics and major comorbidities in heart failure patients more than 85 years of age compared with younger age groups. European journal of heart failure. 2011; 13:1216-1223. [PubMed: 21896536]

34. Bitter T, Faber L, Hering D, Langer C, Horstkotte D, Oldenburg O. Sleep-disordered breathing in heart failure with normal left ventricular ejection fraction. European journal of heart failure. 2009; 11:602-608. [PubMed: 19468022]

35. Ather S, Chan W, Bozkurt B, et al. Impact of noncardiac comorbidities on morbidity and mortality in a predominantly male population with heart failure and preserved versus reduced ejection fraction. Journal of the American College of Cardiology. 2012; 59:998-1005. [PubMed: 22402071]

36. Rijzewijk LJ, van der Meer RW, Smit JW, et al. Myocardial steatosis is an independent predictor of diastolic dysfunction in type 2 diabetes mellitus. Journal of the American College of Cardiology. 2008; 52:1793-1799. [PubMed: 19022158]

37. Myasoedova E, Crowson CS, Nicola PJ, et al. The influence of rheumatoid arthritis disease characteristics on heart failure. The Journal of rheumatology. 2011; 38:1601-1606. [PubMed: 21572155]

38. Davis JM 3rd, Roger VL, Crowson CS, Kremers HM, Therneau TM, Gabriel SE. The presentation and outcome of heart failure in patients with rheumatoid arthritis differs from that in the general population. Arthritis and rheumatism. 2008; 58:2603-2611. [PubMed: 18759286]

39. Roman MJ, Salmon JE. Cardiovascular manifestations of rheumatologic diseases. Circulation. 2007; 116:2346-2355. [PubMed: 17998471] 
40. Bhatia RS, Tu JV, Lee DS, et al. Outcome of heart failure with preserved ejection fraction in a population-based study. The New England journal of medicine. 2006; 355:260-269. [PubMed: 16855266]

41. Maxwell CB, Jenkins AT. Drug-induced heart failure. American journal of health-system pharmacy : AJHP : official journal of the American Society of Health-System Pharmacists. 2011; 68:1791-1804. [PubMed: 21930637]

42. Kane GC, Karon BL, Mahoney DW, et al. Progression of left ventricular diastolic dysfunction and risk of heart failure. JAMA : the journal of the American Medical Association. 2011; 306:856863. [PubMed: 21862747]

43. Lam CS, Lyass A, Kraigher-Krainer E, et al. Cardiac dysfunction and noncardiac dysfunction as precursors of heart failure with reduced and preserved ejection fraction in the community. Circulation. 2011; 124:24-30. [PubMed: 21670229]

44. Velagaleti RS, Gona P, Pencina MJ, et al. Left ventricular hypertrophy patterns and incidence of heart failure with preserved versus reduced ejection fraction. Am J Cardiol. 2014; 113:117-122. [PubMed: 24210333]

45. Neeland IJ, Drazner MH, Berry JD, et al. Biomarkers of chronic cardiac injury and hemodynamic stress identify a malignant phenotype of left ventricular hypertrophy in the general population. $\mathrm{J}$ Am Coll Cardiol. 2013; 61:187-195. [PubMed: 23219305]

46. Cheng JM, Akkerhuis KM, Battes LC, et al. Biomarkers of heart failure with normal ejection fraction: a systematic review. European journal of heart failure. 2013; 15:1350-1362. [PubMed: 23845797]

47. Go AS, Mozaffarian D, Roger VL, et al. Executive summary: heart disease and stroke statistics--2013 update: a report from the American Heart Association. Circulation. 2013; 127:143-152. [PubMed: 23283859]

48. Owan TE, Hodge DO, Herges RM, Jacobsen SJ, Roger VL, Redfield MM. Trends in prevalence and outcome of heart failure with preserved ejection fraction. The New England journal of medicine. 2006; 355:251-259. [PubMed: 16855265]

49. Lim SS, Vos T, Flaxman AD, et al. A comparative risk assessment of burden of disease and injury attributable to 67 risk factors and risk factor clusters in 21 regions, 1990-2010: a systematic analysis for the Global Burden of Disease Study 2010. Lancet. 2012; 380:2224-2260. [PubMed: 23245609]

50. Steinberg BA, Zhao X, Heidenreich PA, et al. Trends in patients hospitalized with heart failure and preserved left ventricular ejection fraction: prevalence, therapies, and outcomes. Circulation. 2012; 126:65-75. [PubMed: 22615345]

51. Roger VL, Weston SA, Redfield MM, et al. Trends in heart failure incidence and survival in a community-based population. Jama. 2004; 292:344-350. [PubMed: 15265849]

52. Murad K, Kitzman DW. Frailty and multiple comorbidities in the elderly patient with heart failure: implications for management. Heart failure reviews. 2012; 17:581-58. [PubMed: 21626426]

53. Vasan RS, Larson MG, Benjamin EJ, Evans JC, Reiss CK, Levy D. Congestive heart failure in subjects with normal versus reduced left ventricular ejection fraction: prevalence and mortality in a population-based cohort. Journal of the American College of Cardiology. 1999; 33:1948-1955. [PubMed: 10362198]

54. Henkel DM, Redfield MM, Weston SA, Gerber Y, Roger VL. Death in heart failure: a community perspective. Circulation Heart failure. 2008; 1:91-97. [PubMed: 19300532]

55. Chan MM, Lam CS. How do patients with heart failure with preserved ejection fraction die? European journal of heart failure. 2013; 15:604-613. [PubMed: 23610137]

56. Campbell RT, Jhund PS, Castagno D, Hawkins NM, Petrie MC, McMurray JJ. What have we learned about patients with heart failure and preserved ejection fraction from DIG-PEF, CHARMpreserved, and I-PRESERVE? Journal of the American College of Cardiology. 2012; 60:23492356. [PubMed: 23141494]

57. Tribouilloy C, Rusinaru D, Mahjoub H, et al. Prognosis of heart failure with preserved ejection fraction: a 5 year prospective population-based study. Eur Heart J. 2008; 29:339-347. [PubMed: $18156618]$ 
58. Somaratne JB, Berry C, McMurray JJ, Poppe KK, Doughty RN, Whalley GA. The prognostic significance of heart failure with preserved left ventricular ejection fraction: a literature-based meta-analysis. Eur J Heart Fail. 2009; 11:855-862. [PubMed: 19654140]

59. Ntusi NB, Mayosi BM. Epidemiology of heart failure in sub-Saharan Africa. Expert review of cardiovascular therapy. 2009; 7:169-180. [PubMed: 19210213]

60. Dunlay SM, Redfield MM, Weston SA, et al. Hospitalizations after heart failure diagnosis a community perspective. Journal of the American College of Cardiology. 2009; 54:1695-1702. [PubMed: 19850209]

61. Chen J, Normand SL, Wang Y, Krumholz HM. National and regional trends in heart failure hospitalization and mortality rates for Medicare beneficiaries, 1998-2008. JAMA : the journal of the American Medical Association. 2011; 306:1669-1678. [PubMed: 22009099]

62. Shah AM, Shah SJ, Anand IS, et al. Cardiac structure and function in heart failure with preserved ejection fraction: baseline findings from the echocardiographic study of the treatment of preserved cardiac function heart failure with an aldosterone antagonist trial. Circulation Heart failure. 2014; 7:104-115. [PubMed: 24249049]

63. Solomon SD, Zile M, Pieske B, et al. The angiotensin receptor neprilysin inhibitor LCZ696 in heart failure with preserved ejection fraction: a phase 2 double-blind randomised controlled trial. Lancet. 2012; 380:1387-1395. [PubMed: 22932717]

64. Zile MR, Gottdiener JS, Hetzel SJ, et al. Prevalence and significance of alterations in cardiac structure and function in patients with heart failure and a preserved ejection fraction. Circulation. 2011; 124:2491-2501. [PubMed: 22064591]

65. Persson H, Lonn E, Edner M, et al. Diastolic dysfunction in heart failure with preserved systolic function: need for objective evidence:results from the CHARM Echocardiographic SubstudyCHARMES. J Am Coll Cardiol. 2007; 49:687-694. [PubMed: 17291934]

66. Yusuf S, Pfeffer MA, Swedberg K, et al. Effects of candesartan in patients with chronic heart failure and preserved left-ventricular ejection fraction: the CHARM-Preserved Trial. Lancet. 2003; 362:777-781. [PubMed: 13678871]

67. Lam CS, Roger VL, Rodeheffer RJ, et al. Cardiac structure and ventricular-vascular function in persons with heart failure and preserved ejection fraction from Olmsted County, Minnesota. Circulation. 2007; 115:1982-1990. [PubMed: 17404159]

68. Maurer MS, Burkhoff D, Fried LP, Gottdiener J, King DL, Kitzman DW. Ventricular structure and function in hypertensive participants with heart failure and a normal ejection fraction: the Cardiovascular Health Study. J Am Coll Cardiol. 2007; 49:972-981. [PubMed: 17336721]

69. He KL, Burkhoff D, Leng WX, et al. Comparison of ventricular structure and function in Chinese patients with heart failure and ejection fractions $>55 \%$ versus $40 \%$ to $55 \%$ versus $<40 \%$. Am J Cardiol. 2009; 103:845-851. [PubMed: 19268743]

70. Gupta DK, Shah AM, Castagno D, et al. Heart Failure with Preserved Ejection Fraction in AfricanAmericans - The Atherosclerosis Risk in Communities (ARIC) Study. JACC Heart failure. 2013; 1:156-163. [PubMed: 23671819]

71. Klapholz M, Maurer M, Lowe AM, et al. Hospitalization for heart failure in the presence of a normal left ventricular ejection fraction: results of the New York Heart Failure Registry. J Am Coll Cardiol. 2004; 43:1432-1438. [PubMed: 15093880]

72. Katz DH, Beussink L, Sauer AJ, Freed BH, Burke MA, Shah SJ. Prevalence, clinical characteristics, and outcomes associated with eccentric versus concentric left ventricular hypertrophy in heart failure with preserved ejection fraction. Am J Cardiol. 2013; 112:1158-1164. [PubMed: 23810323] 


\section{Key points}

- Heart failure with preserved ejection fraction (HFPEF) is a common disease, especially among the elderly and in women.

- With an increasing prevalence of hypertension, obesity, atrial fibrillation, and diabetes, and the growing elderly segment of the general population, the prevalence of HFPEF is projected to increase in the future.

- HFPEF presents a diagnostic challenge and studies differ widely in their reported incidence and mortality rates associated with this condition.

- There is agreement that between a third and one half of heart failure patients in the community have HFPEF.

- Prognosis is overall poor. Patients with HFPEF have substantial comorbidity, high rates of repeated hospitalizations, and a high mortality. 
Table 1

Framingham criteria for congestive heart failure ( 2 major, or 1 major +2 minor criteria are required)

Major:
Paroxysysmal nocturnal dyspnea
Neck vein distension
Rales
Radiographic cardiomegaly
Acute pulmonary edema
Third sound gallop
Increased central venous pressure
Increased circulation time ( 25 seconds)
Hepatojugular reflux
Pulmonary edema, visceral congestion, or cardiomegaly on autopsy
Weight loss 24.5 kg in 5 days in response to treatment of heart failure
Minor:
Bilateral ankle edema
Noctural cough
Dyspnea on ordinary exertion
Hepatomegaly
Pleural effusion
Decrease in vital capacity by $33 \%$ of maximal value recorded
Tachycardia ( $\geq 120$ beats per minute)




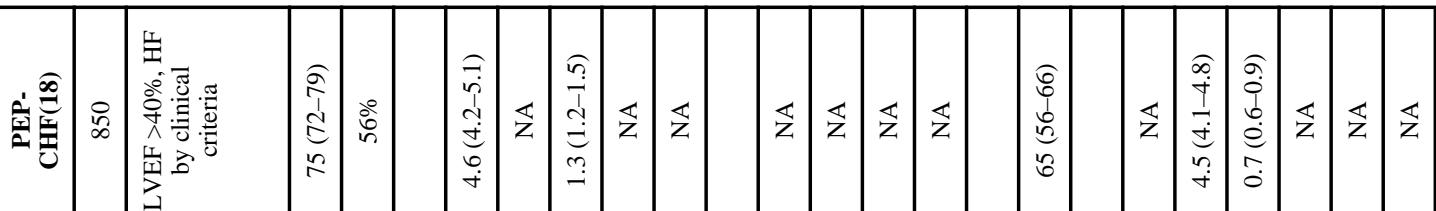

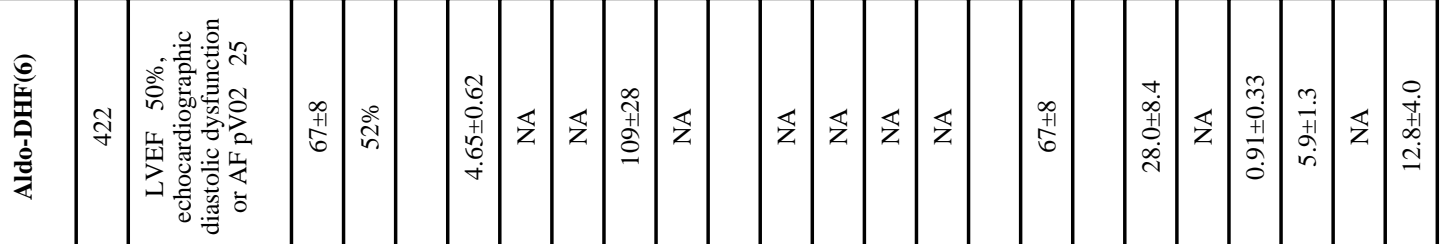

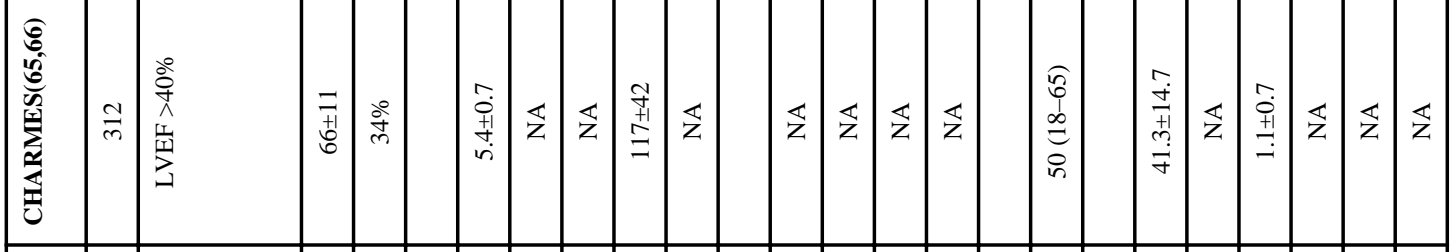

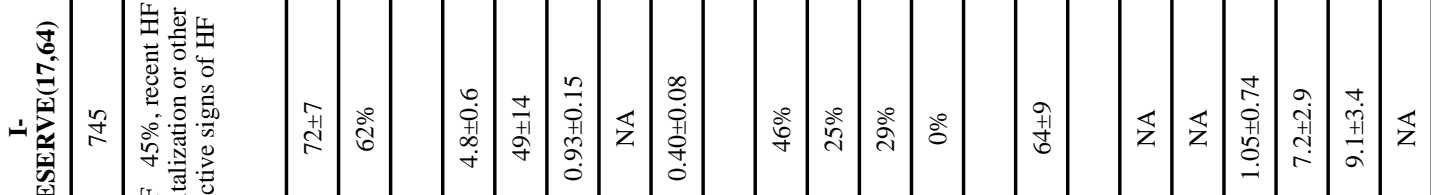

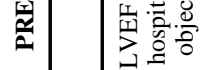

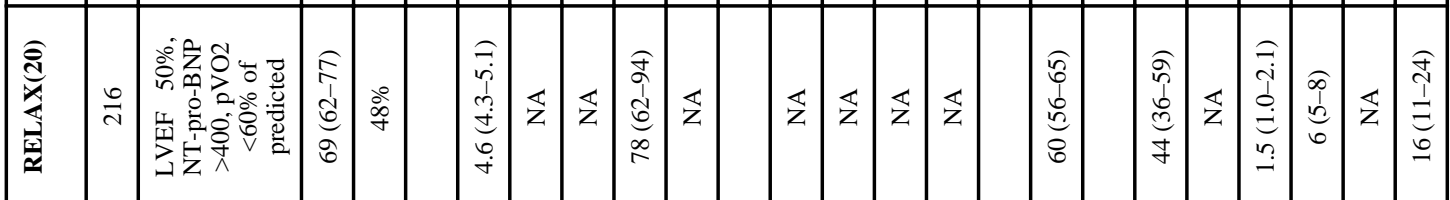

\begin{tabular}{|c|c|c|c|c|c|c|c|c|c|c|c|c|c|c|c|c|c|c|c|c|}
\hline 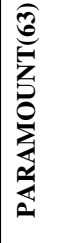 & รี & 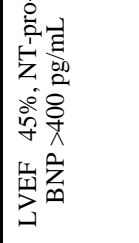 & 站 & 总 & & $\begin{array}{l}0 \\
0 \\
+ \\
+1 \\
+ \\
+ \\
+\end{array}$ & 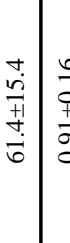 & 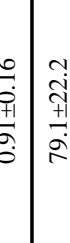 & 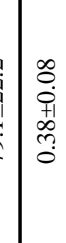 & & \ั\ & 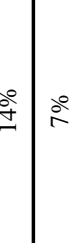 & 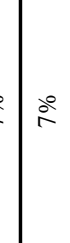 & & & 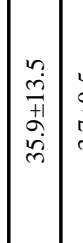 & 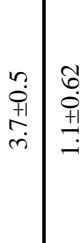 & 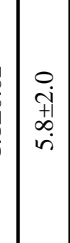 & & 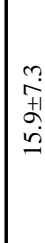 \\
\hline 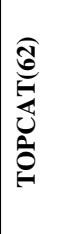 & \% & 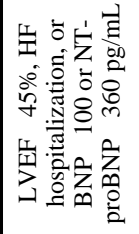 & 产 & g̊ & & 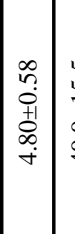 & 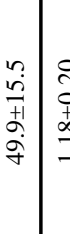 & 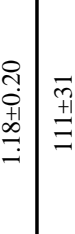 & \begin{tabular}{l}
0 \\
0 \\
0 \\
+1 \\
\multirow{1}{0}{} \\
0
\end{tabular} & & $\frac{10}{9}$ & 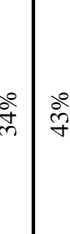 & $5^{\circ}$ & & & 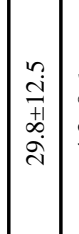 & 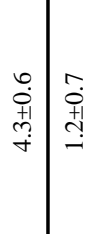 & $\begin{array}{l}\pi \\
\pm \\
0 \\
0\end{array}$ & \begin{tabular}{l}
1 \\
\multirow{1}{1}{} \\
\multirow{1}{1}{} \\
$\infty$
\end{tabular} & 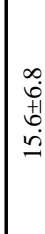 \\
\hline 总 & $\mathrm{z}$ & 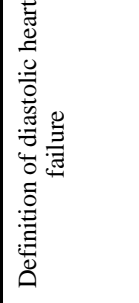 & & (ي) & 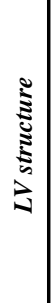 & 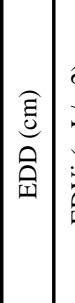 & 胥 & 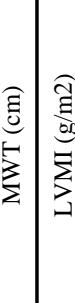 & 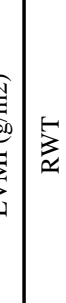 & 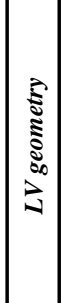 & 愛 & 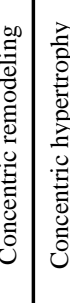 & 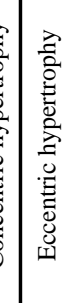 & 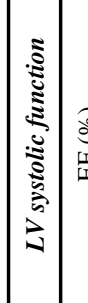 & 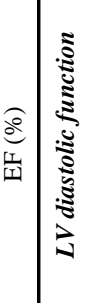 & 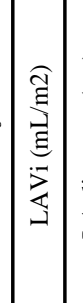 & 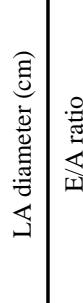 & 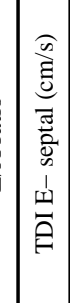 & 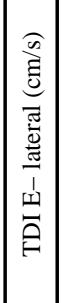 & 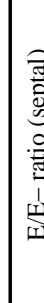 \\
\hline
\end{tabular}




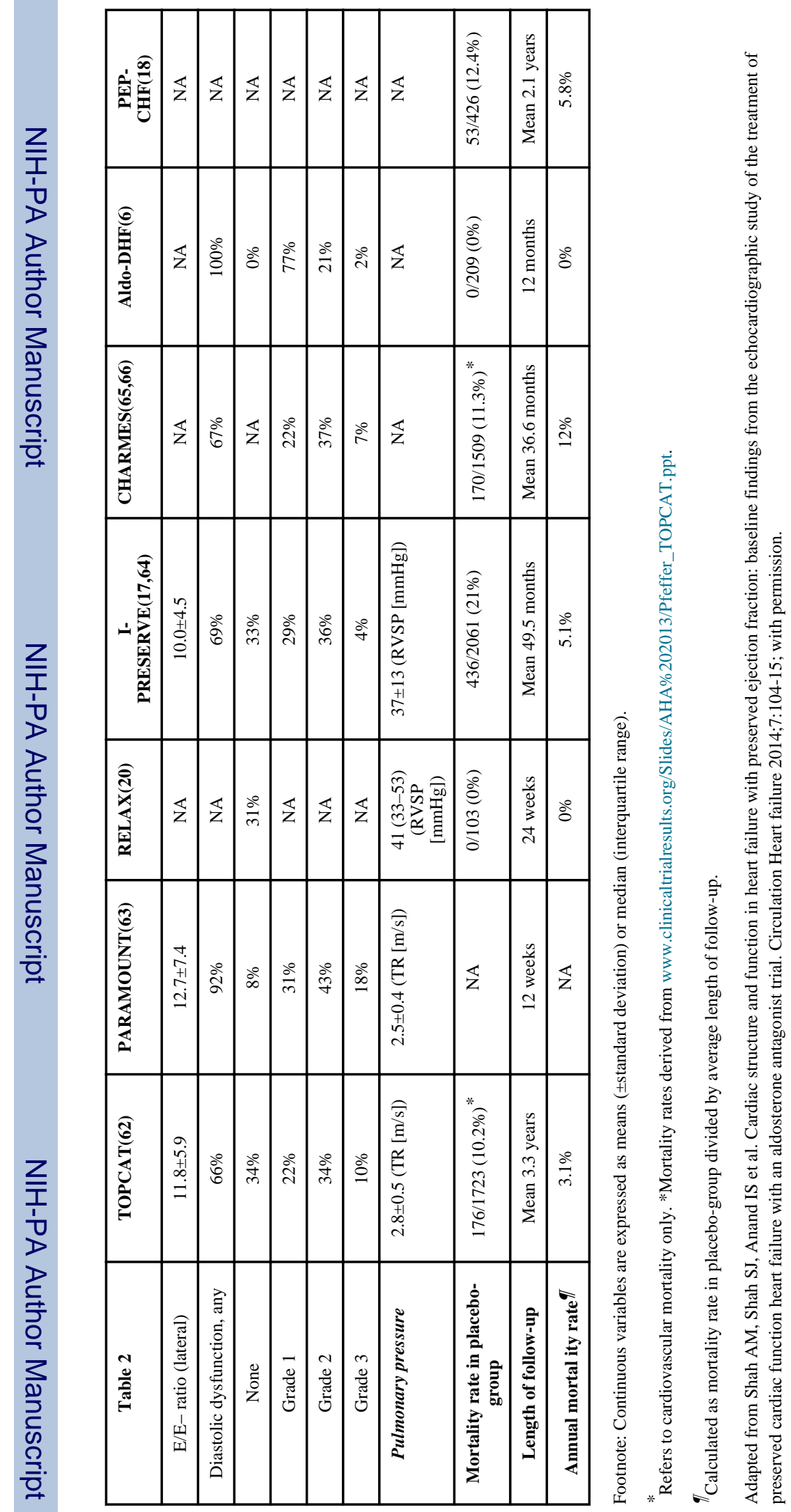




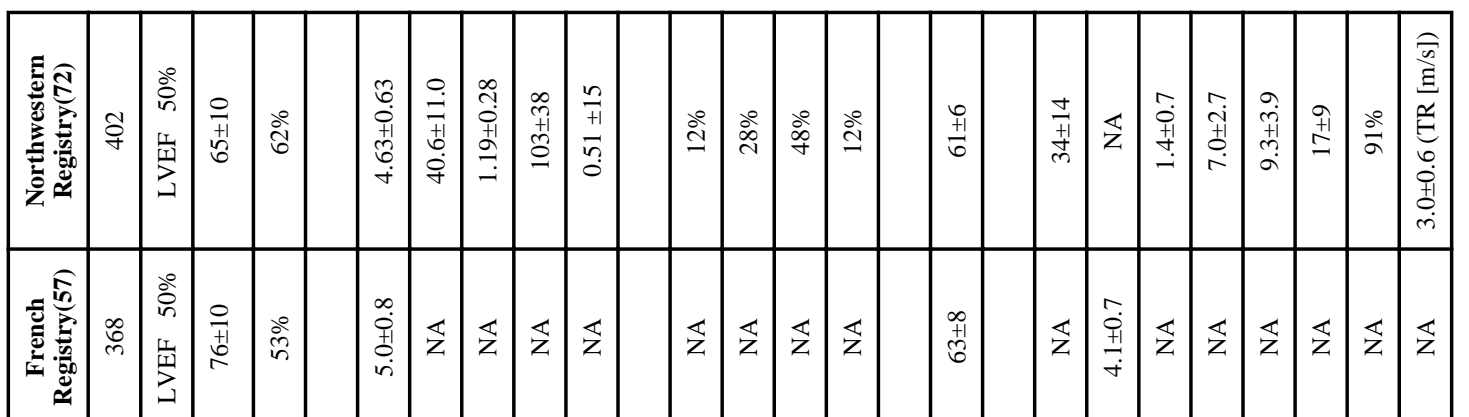

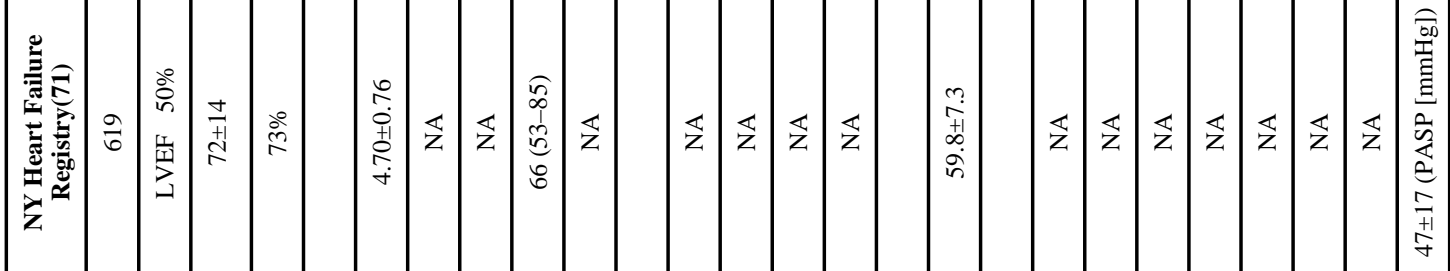

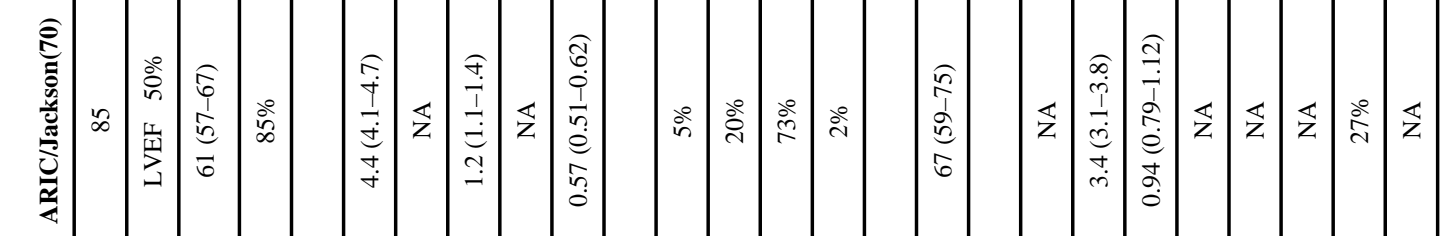

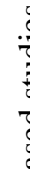

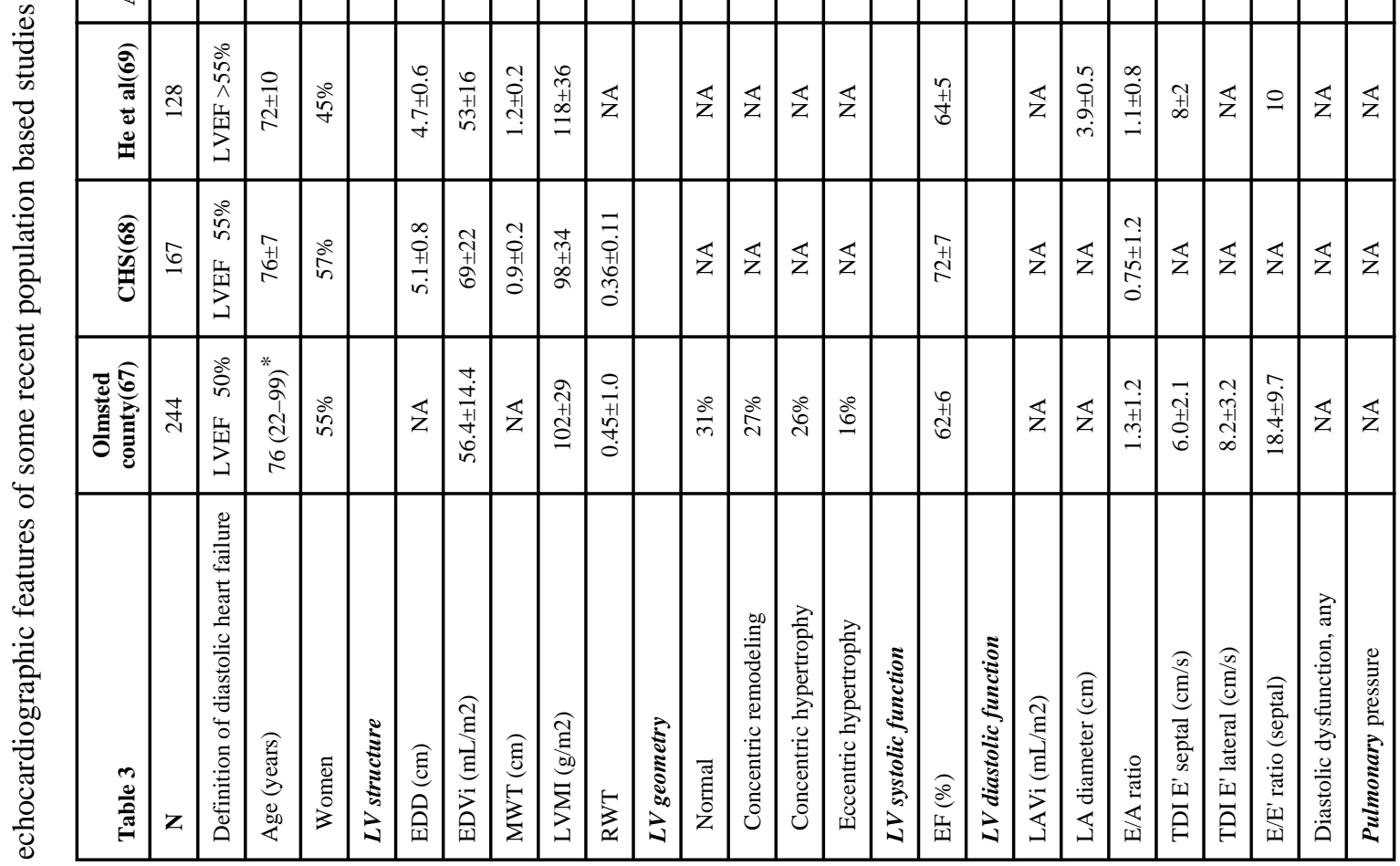




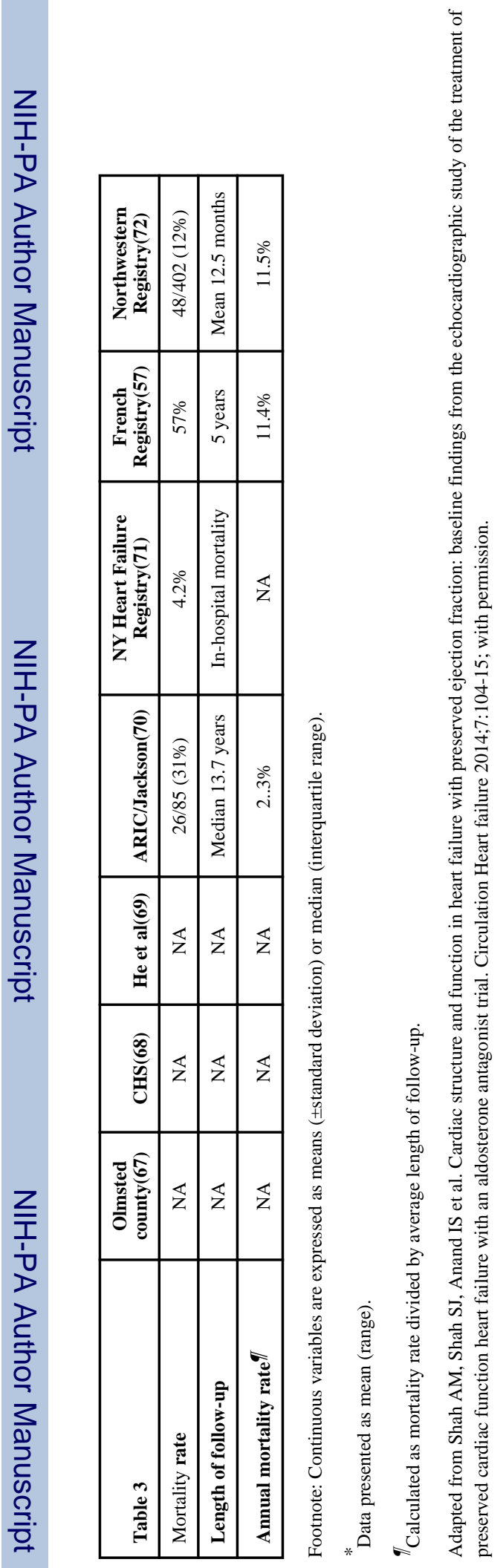

Heart Fail Clin. Author manuscript; available in PMC 2015 July 01. 